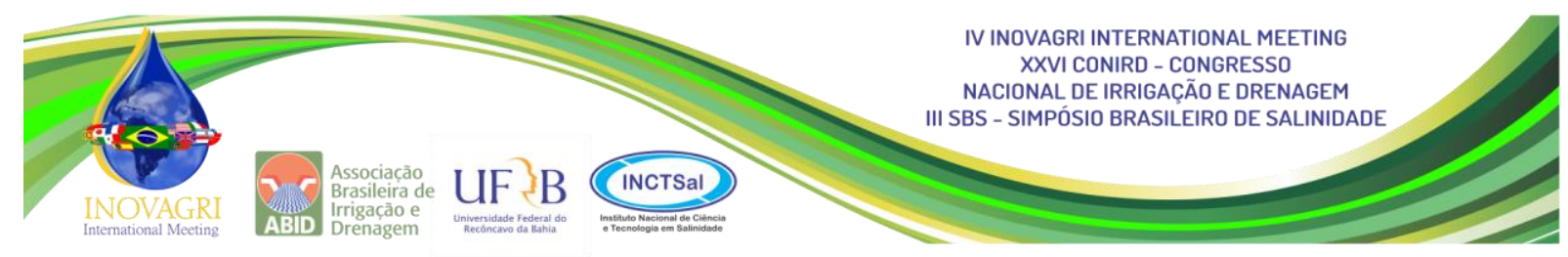

\title{
ASPECTOS FISIOLÓGICOS DE VARIEDADES DE CANA-DE-AÇÚCAR SUBMETIDAS A ESTRESSE SALINO
}

\author{
W. L. Simões ${ }^{1}$, M. Calgaro ${ }^{2}$, D. S. Coelho ${ }^{3}$, A. C. Mesquita ${ }^{4}$, \\ D. B. dos $\operatorname{Santos}^{5}$, M. A. de Souza ${ }^{6}$
}

RESUMO: As áreas salinizadas têm limitado a produção de culturas como a cana-de-açúcar, sendo a seleção de variedades mais tolerantes ao estresse salino uma das alternativas para os produtores. Objetivo do presente trabalho foi avaliar as respostas fisiológicas de três variedades de cana-de-açúcar à salinidade. $\mathrm{O}$ experimento foi realizado em vasos, numa casa de vegetação localizada no campo experimental da Embrapa Semiárido, em Petrolina-PE. O delineamento experimental utilizado foi em blocos casualizados dispostos em arranjo fatorial de 6 X 3, sendo seis níveis de salinidade da água de irrigação $(0 ; 1,0 ; 2,0 ; 4,0 ; 6,0$ e 8,0 dS m ${ }^{1}$ ) e três variedades de cana-de-açúcar (VAT 90212, RB 867515 e RB 835089). As variedades de cana-de-açúcar demonstraram alteração nas trocas gasosas com o aumento da salinidade, com destaque à maior tolerância para as variedade RB 867515 e RB 835089.

PALAVRAS-CHAVES: Trocas gasosas, Saccharum officinarum, fotossíntese

\section{PHYSIOLOGICAL ASPECTS OF SUGARCANE VARIETIES SUBJECTED TO SALINE STRESS}

\begin{abstract}
The salinized areas have limited the production of crops such as sugarcane, and the selection of varieties that are more tolerant to salt stress is one of the alternatives for producers. The objective of the present study was to evaluate the physiological responses of three varieties of sugarcane to salinity. The experiment was carried out in pots, in a greenhouse located in the experimental field of Embrapa Semiarid, in Petrolina-PE. The experimental design was randomized blocks arranged in a factorial arrangement of $6 \times 3$, with six levels of irrigation water salinity $(0,1.0,2.0,4.0,6.0$ and $8.0 \mathrm{dS} \mathrm{m}-1)$ and three varieties of sugar cane (VAT 90212, RB 867515 e RB 835089) The sugarcane varieties
\end{abstract}

\footnotetext{
${ }^{1}$ Engenheiro Agrônomo, pesquisador da Embrapa Semiárido, e-mail: welson.simoes@embrapa.br;

${ }^{2}$ Engenheiro Agrônomo, pesquisador da Embrapa Semiárido, e-mail: marcelo.calgaro@embrapa.br

${ }^{3}$ Engenheira Agrícola e Ambiental, doutoranda UFRPE, e-mail: daniela.coelho@ hotmail.com.br

${ }^{4}$ Engenheira Agrônomo, professor da UNEB Juazeiro-Ba, e-mail: alessandro.mesq@yahoo.com.br

${ }^{5}$ Engenheiro Agrônomo, professor do IF Baiano Serrinha-Ba, e-mail: delfran.batista@gmail.com

${ }^{6}$ Biólogo, Doutorando UFLA, e-mail: moisesalves-1989@hotmail.com
} 
showed an alteration in the gas exchange with the increased salinity, with the highest tolerance for the variety RB 867515 and RB 835089.

KEYWORDS: Gas exchange, Saccharum officinarum, photosynthesis

\section{INTRODUÇÃO}

O Nordeste brasileiro apresenta grande potencial para produção de cana-de-açúcar, sendo a produção estimada em 61,2 milhões de toneladas, representando 9,34\% da produtividade brasileira (CONAB, 2015). Por outro lado, o semiárido brasileiro caracteriza-se por apresentar condições edafoclimáticas favoráveis à salinização do solo e das águas disponíveis nas propriedades para os produtores (Willadino et al., 2011), tornando os seus usos inviáveis para o cultivo de diversas espécies comerciais.

Os principais problemas causados pela salinização do solo são a redução do potencial osmótico da sua solução, diminuindo sua disponibilidade de água e acentuando a toxicidade de certos íons às plantas (Bernardo, 2006). Segundo Blumwald (2000), solos salinos provocam estresse osmótico, resultante das altas concentrações de soluto no solo, e estresse iônico ocasionado pela queda na razão $\mathrm{K}^{+} / \mathrm{Na}^{+}$, alterando homeostase celular.

Durante o estresse salino, a fotossíntese e o crescimento celular são afetados diretamente com a queda na disponibilidade de $\mathrm{CO}_{2}$ (Flexas et al., 2007) e alterações no metabolismo fotossintético (Lawlor e Cornic, 2002). Um dos mecanismos utilizados pelas plantas para adaptar-se a este meio é o ajustamento osmótico, o qual permite a diminuição do seu potencial osmótico através do acúmulo de íons e solutos orgânicos fazendo com que se mantenha um gradiente de potencial de água favorável para absorver água e manter uma pressão de turgor (MUNNS et al., 2016).

Desse modo, a avaliação dos mecanismos desenvolvidos pelas plantas para ajustar-se ao estresse salino torna-se importante na identificação de genótipos mais tolerantes. Sabe-se que a cana-de-açúcar é considerada moderadamente sensível à salinidade, sendo que a diminuição do rendimento pode chegar a $50 \%$ em solos moderadamente salinizados, tendo oscilações entre as variedades.

Diante do exposto, o presente trabalho teve como objetivo avaliar as respostas fisiológicas de três variedades de cana-de-açúcar submetidas a diferentes níveis de salinidades no solo. 
Para cada vaso foram plantadas duas gemas de cana-de-açúcar, obtidas da área de cultivo da Agroindústria do Vale do São Francisco (Agrovale). Em seguida, o solo dos vasos foi umedecido até a capacidade de campo, com uso de água sem adição de sais.

As águas salinas utilizadas nas irrigações foram preparadas a partir dos sais $\mathrm{NaCl}$, $\mathrm{CaCl}_{2} .2 \mathrm{H}_{2} \mathrm{O}$ e $\mathrm{MgSO}_{4} .7 \mathrm{H}_{2} \mathrm{O}$, de modo a se obter proporção equivalente entre $\mathrm{Na}: \mathrm{Ca}: \mathrm{Mg}$ de 7:2:1 (Aquino et al., 2007). As águas preparadas foram renovadas semanalmente e armazenadas em local fresco e sombreado, a fim de evitar alterações do seu valor por possíveis evaporações e variações da temperatura.

Após 60 dias de estresse salino foram avaliadas as trocas gasosas através do analisador portátil de gás infravermelho (IRGA), modelo Li-6400, utilizando luz artificial fixada em $2000 \mu \mathrm{mol} \mathrm{m} \mathrm{m}^{-2} \mathrm{~s}^{-1}$. As variáveis analisadas foram: taxa de fotossíntese (A), condutância estomática $\left(\mathrm{g}_{\mathrm{s}}\right)$ e transpiração $(\mathrm{E})$. $\mathrm{O}$ índice de clorofila total foi determinado a partir de leituras realizadas em três pontos da folha +3 , utilizando o clorofilômetro da marca comercial ClorofiLOG modelo CFL 1030.

Os dados obtidos foram submetidos à análise de variância utilizando o programa Sisvar 5.0. Para as situações em que houve interação significativa entre as variedades e níveis de salinidade, foi realizado o desdobramento das variáveis dentro de cada fator, caso contrário, considerou-se o efeito independente dos fatores para as variáveis estudadas.

Para comparação entre os níveis de salinidade foram avaliados modelos de regressão de primeiro e segundo grau quando significativos até $5 \%$ de probabilidade. Para comparação entre as variedades foi realizado o teste de Tukey a 5\% de probabilidade (Ferreira, 2014).

\section{RESULTADOS E DISCUSSÃO}

Notou-se que a imposição do estresse salino nas três cultivares de cana-de-açúcar apenas não apresentou diferença significativa para a interação entre variedades e condutividade elétrica da água de irrigação para a variável teor de clorofila.

Em relação ao índice de clorofila, houve influência do nível de salinidade sobre essa variável independente da variedade estudada, bem como, houve diferenças entre variedades, independente do efeito do estresse salino.

O maior índice de clorofila foi obtido para variedade RB 835089 (Figura 1A). Como as clorofilas desempenham papel importante na fotossíntese, sendo responsáveis pela captação de energia luminosa para as reações fotoquímicas (Taiz \& Zeiger, 2013), maiores índices de 
clorofila favorecem as trocas gasosas, podendo, de certa forma, contribuir para adaptação dessas variedades as condições de estresse salino. Entre essas variedades citadas, Simões et al. (2016), relatam que a RB 835089 foi o que apresentou o maior número de folhas, diâmetro do caule e peso da planta. Isso corrobora com a importância da clorofila na realização da fotossíntese e consequentemente, acumulação de fotoassimilados e crescimento da planta.

Por outro lado, Willadino et al. (2011), avaliando a mesma variedade de cana RB 867515, observou que a redução no teor de clorofila seria um mecanismo de proteção da planta, por diminuir a captação de energia luminosa e consequentemente reduzir o fluxo de elétrons para a cadeia de transporte de elétrons, em sintonia com a redução da assimilação de $\mathrm{CO}_{2}$, uma vez que essa está altamente reduzida favorecendo a redução parcial do oxigênio que resulta na formação de espécies reativas de oxigênio (ROS) (BROSCHÉ et al., 2010).

Independentemente das variedades analisadas, à medida que houve aumento da condutividade elétrica esse índice foi elevando-se linearmente (Figura 1B), o que pode representar menor susceptibilidade ao estresse, uma vez que Jamil et al. (2007), afirmam que normalmente ocorre redução nos teores de clorofila em plantas sensíveis à salinidade, ocorrendo o inverso em plantas mais tolerantes. Silva et al. (2013), demonstraram que plantas de cana-de-açúcar com longo tempo de seca, cerca de 90 dias, tiveram redução no teor de clorofila, pelo índice SPAD, sendo mais severa em genótipos susceptíveis.
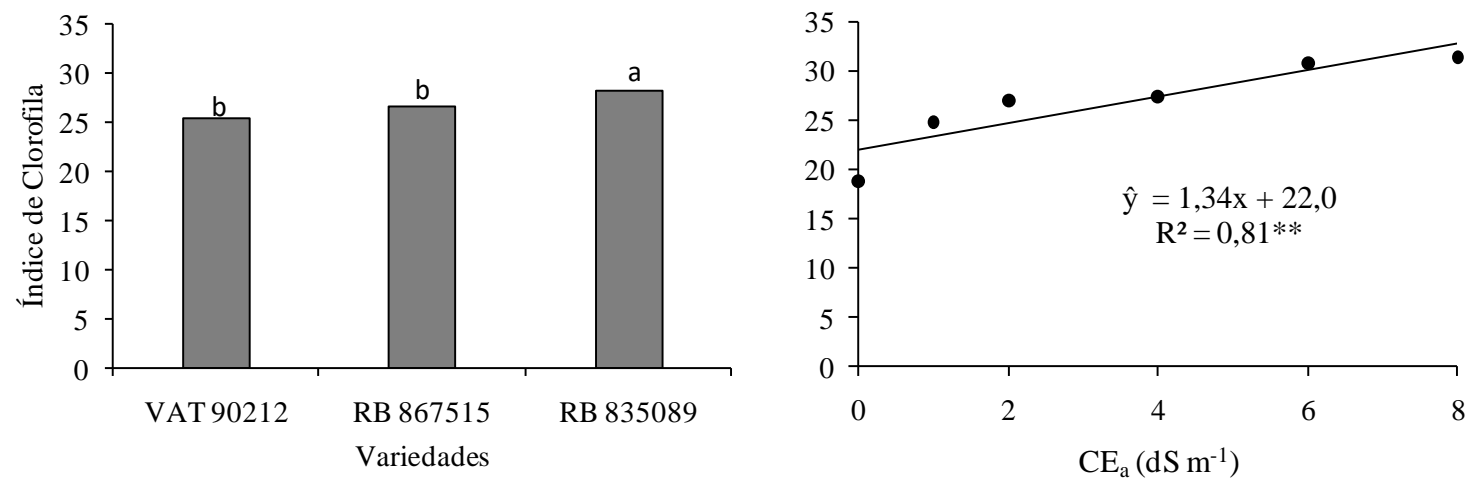

Figura 1. Índices de clorofila para folhas de três variedades de cana-de-açúcar e em resposta a diferentes níveis de salinidade. Colunas de mesma letra não diferem entre si pelo teste de Tukey a 5\% de probabilidade. ** regressão significativa à $5 \%$ de probabilidade.

O estresse salino proporcionou alteração da taxa fotossintética das variedades de canade-açúcar testadas (Tabela 2) o que, portanto, pode estar associado à alteração também ocorrida com a condutância estomática (Tabela 3). Através dos resultados obtidos, nota-se que a imposição da salinidade nas diferentes variedades de cana-de-açúcar proporcionou significativa variação também na transpiração das plantas (Tabelas 4). 
O aumento nos níveis de salinidade levou ao fechamento estomático, como consequência da redução da disponibilidade de água, causando significativa diminuição na transpiração (E) para a variedade RB 835089 e, consequentemente, uma redução na condutância estomática ( $g s$ ) (Tabela 3), que sinaliza ser uma estratégia para diminuir a perda de água pela transpiração, sendo, portanto, um mecanismo de resistência da planta.

A redução da $g s$ resultou na diminuição das taxas fotossintéticas $(A)$ com exceção para variedades RB 867515 (Tabela 2), o que pode representar uma maior adaptabilidade dessa variedade ao estresse salino, mesmo tendo essa variedade apresentado uma redução no teor de clorofila (Figura 1A).

Tabela 2. Taxa de fotossíntese (A) em variedades de cana-de-açúcar submetidas a diferentes níveis de salinidade. Colunas de mesma letra não diferem entre si pelo teste de Tukey a $5 \%$ de probabilidade. ** regressões significativas à $1 \%$ de probabilidade, respectivamente.

\begin{tabular}{|c|c|c|c|c|c|c|c|c|}
\hline \multirow[b]{2}{*}{$\mu \mathrm{mol} \mathrm{CO} 2 \mathrm{~m}^{-2} \mathrm{~s}^{-1}$} & \multicolumn{6}{|c|}{$\mathrm{CE}_{\mathrm{a}}\left(\mathrm{dS} \mathrm{m} \mathrm{m}^{-1}\right)$} & \multirow{2}{*}{$\begin{array}{l}\text { Equação de } \\
\text { regressão }\end{array}$} & \multirow{2}{*}{$\mathrm{R}^{2}$} \\
\hline & 0,0 & 1,0 & 2,0 & 4,0 & 6,0 & 8,0 & & \\
\hline VAT 90212 & $37,1 \mathrm{a}$ & $23,6 \mathrm{~b}$ & $18,4 \mathrm{~b}$ & $11,0 \mathrm{~b}$ & $13,6 \mathrm{~b}$ & $9,8 \mathrm{~b}$ & $\hat{y}=0,70 x^{2}-8,3 x+34$ & $91,4 * *$ \\
\hline RB 867515 & $28,3 \mathrm{~b}$ & $23,0 \mathrm{~b}$ & $13,7 \mathrm{~b}$ & $22,9 \mathrm{a}$ & $23,8 \mathrm{a}$ & $18,6 \mathrm{a}$ & $\hat{y}=\bar{y}$ & -- \\
\hline RB 835089 & $46,9 \mathrm{a}$ & $32,5 \mathrm{a}$ & $27,6 \mathrm{a}$ & $23,4 \mathrm{a}$ & $27,6 \mathrm{a}$ & $24,7 \mathrm{a}$ & $\hat{y}=0,72 x^{2}-7,7 x+43$ & $81,9 * *$ \\
\hline
\end{tabular}

Contudo, quando se observa o comportamento das variedades em cada nível de salinidade aplicado, destaca-se que com a aplicação de $8,0 \mathrm{dS} \mathrm{\textrm {m } ^ { - 1 }}$ não houve diferença significativa entre as variedades analisadas com relação a taxa de transpiração $(E)$ (Tabela 3) e condutância estomática ( $g s)$ (Tabela 4). Porém, neste nível de salinidade, a taxa fotossintética foi superior para as variedades RB 867515 e RB835089, indicando menor sensibilidade ao estresse salino para esta característica, quando comparado com a VAT 90212.

Tabela 3. Condutância estomática (gs) em variedades de cana-de-açúcar submetidas a diferentes níveis de salinidade. Colunas de mesma letra não diferem entre si pelo teste de Tukey a $5 \%$ de probabilidade. *, ** regressões significativas à 5 e $1 \%$ de probabilidade, respectivamente.

\begin{tabular}{cccccccccc}
\hline & \multicolumn{10}{c}{$\left.\mathrm{CEa}(\mathrm{dS} \mathrm{m})^{-1}\right)$} & & \\
\cline { 2 - 7 } mol m$^{-2} \mathrm{~s}^{-1}$ & 0,0 & 1,0 & 2,0 & 4,0 & 6,0 & 8,0 & equação de regressão & $\mathrm{R}^{2}$ & \\
\hline VAT 90212 & $0,31 \mathrm{~b}$ & $0,16 \mathrm{a}$ & $0,12 \mathrm{a}$ & $0,07 \mathrm{~b}$ & $0,10 \mathrm{~b}$ & $0,13 \mathrm{a}$ & $\hat{\mathrm{y}}=0,01 \mathrm{x}^{2}-0,09 \mathrm{x}+0,28$ & $90,6^{* *}$ \\
RB 867515 & $0,32 \mathrm{~b}$ & $0,17 \mathrm{a}$ & $0,12 \mathrm{a}$ & $0,20 \mathrm{a}$ & $0,19 \mathrm{a}$ & $0,16 \mathrm{a}$ & $\hat{\mathrm{y}}=-0,01 \mathrm{x}+0,22$ & $17,9^{*}$ \\
RB 835089 & $0,29 \mathrm{~b}$ & $0,22 \mathrm{a}$ & $0,19 \mathrm{a}$ & $0,18 \mathrm{a}$ & $0,25 \mathrm{a}$ & $0,15 \mathrm{a}$ & $\hat{\mathrm{y}}=\overline{\mathrm{y}}$ & -- \\
\hline
\end{tabular}


Tabela 4. Transpiração (E) em variedades de cana-de-açúcar submetidas a diferentes níveis de salinidade. Colunas de mesma letra não diferem entre si pelo teste de Tukey a $5 \%$ de probabilidade. *, ** regressões significativas à 5 e $1 \%$ de probabilidade, respectivamente

\begin{tabular}{|c|c|c|c|c|c|c|c|c|}
\hline \multirow[b]{2}{*}{$\mathrm{mol} \mathrm{H}_{2} \mathrm{O} \mathrm{m}^{-2} \mathrm{~s}^{-1}$} & \multicolumn{6}{|c|}{$\mathrm{CE}_{\mathrm{a}}\left(\mathrm{dS} \mathrm{m} \mathrm{m}^{-1}\right)$} & \multirow{2}{*}{ equação de regressão } & \multirow{2}{*}{$\mathrm{R}^{2}$} \\
\hline & 0,0 & 1,0 & 2,0 & 4,0 & 6,0 & 8,0 & & \\
\hline VAT 90212 & $8,2 \mathrm{a}$ & $4,5 \mathrm{a}$ & $3,4 \mathrm{a}$ & $1,9 \mathrm{~b}$ & $2,7 \mathrm{~b}$ & $3,8 \mathrm{a}$ & $\hat{y}=0,24 x^{2}-2,4 x+7,4$ & $92,0^{* *}$ \\
\hline RB 867515 & $8,1 \mathrm{a}$ & $4,7 \mathrm{a}$ & $3,4 \mathrm{a}$ & $5,2 \mathrm{a}$ & $5,3 \mathrm{a}$ & $4,4 \mathrm{a}$ & $\hat{y}=\bar{y}$ & -- \\
\hline RB 835089 & $7,9 \mathrm{a}$ & $6,1 \mathrm{a}$ & $5,2 \mathrm{a}$ & $4,9 \mathrm{a}$ & $6,5 \mathrm{a}$ & $4,3 \mathrm{a}$ & $\hat{y}=-0,26 x+6,8$ & $40,8^{*}$ \\
\hline
\end{tabular}

Alguns genótipos de cana-de-açúcar mostram rápida recuperação após eventos de seca (Landell et al., 2005), sendo a tolerância à seca relacionada a mecanismos fisiológicos capazes de manter o crescimento da planta em condição restritiva, tais como fechamento estomático e manutenção da atividade fotossintética (Machado et al., 2009). O fechamento estomático causou significativa diminuição na gs e E em algumas variedades (Tabelas Figuras $3,4)$, sendo que a diminuição de gs nesses tratamentos pode ser uma estratégia para diminuir a perda de água pela transpiração (Inman-Bamber e Smith, 2005; Inman-Bamber et al., 2008), sendo, portanto, um mecanismo de resistência da cultura.

Com base no citado anteriormente, podemos embasar ainda mais a hipotese de que a variedade RB867515 seja realmente tolerante ao stress salino. O stress salino isolado ou simultâneo às variedades de cana-de-açúcar limitou a fotossíntese pelo fechamento estomático (Tabela 2 e 3), o que pode segundo Chaves et al. (2002), ter acarretado uma menor disponibilidade de $\mathrm{CO}_{2}$ para a produção de carboidratos.

\section{CONCLUSÃO}

As variedades RB 835089 e RB 867515 demonstram indícios de tolerância fisiológicas à salinidade, destacando-se a RB 835089 com relação ao índice de clorofila.

\section{REFERÊNCIAS BIBLIOGRÁFICAS}

AQUINO, A. J. S.; LACERDA, C. F.; GOMES-FILHO, E. Crescimento, partição de matéria seca e retenção de $\mathrm{Na}^{+}, \mathrm{K}^{+}$e $\mathrm{Cl}^{-}$em dois genótipos de sorgo irrigados com águas salinas. Revista Brasileira de Ciência do Solo, v.31, p.961-971, 2007. 
BERNARDO, S. Manejo da irrigação na cana-de-açúcar. Revista Alcoobrás, São Paulo, n.106, p.72-80, 2006.

BLUMWALD, E. Sodium transport and salt tolerance in plant cells. Current Opinion of Cell Biology, v.12, p.76-112, 2000.

BROSCHÉ, M.; OVERMYER，K.; WRZACZECK，M. L.; KANGASJÄRVI，J. Stress Signaling III: Reactive Oxygen Species (ROS) in: Pareek, A.; Sopory, S.K.; Bohnert, H. J.; Govindjee Abiotic Stress Adaptation in Plants Springer 91-103, 2010.

CHAVES, M.M.; PEREIRA, J.S.; MAROCO, J.; RODRIGUES, M.L.; RICARDO, C.P.P., OSÓRIO, M.L.; CARVALHO, I.; FARIA, T.; PINHEIRO, C. How plants cope with water stress in the field: Photosynthesis and growth. Annals of Botany, v.89, p. 907-916, 2002.

COMISSÃO ESTADUAL DE FERTILIDADE DO SOLO. Manual de adubação e calagem para o Estado da Bahia. $2^{\mathrm{a}}$ ed. Salvador, 1989. 176p.

CONAB - Companhia Nacional de Abastecimento (2015) Acompanhamento da safra brasileira: Cana-de-Açúcar. v.2 - safra 2015/2016 - n.2, segundo levantamento. Brasília, Embrapa. p.1-30.

FLEXAS, J.; DIAZ-ESPEJO, A.; GALMÉS, J.; KALDENHOFF, R.; MEDRANO, H.; RIBAS-CARBO, M. Rapid variations of mesophyll conductance in response to changes in CO2 concentration around leaves. Plant Cell and Environment, v.30, p.1284-1298, 2007.

INMAN-BAMBER， N.G.; BONNETT， G.D; SPILLMAN， M.F.; HEWITT, M.L.; JACKSON, J. Increasing sucrose accumulation in sugarcane by manipulating leaf extension and photosynthesis with irrigation. Australian Journal of Agricultural Research, v.59, p.13-26, 2008.

INMAN-BAMBER, N.G.; SMITH, D.M. Water relations in sugarcane and response to water deficits. Field Crops Research, v.92, p.185-202, 2005.

LAWLOR ,D. W., CORNIC, G. Photosynthetic carbon assimilation and associated metabolism in relation to water deficits in higher plants. Plant, Cell and Environment 25, 275-294, 2002.

JAMIL, M. et al. Salinity reduced growth PS2 photochemistry and chlorophyll content in radish. Scientia Agricola, v.64, n.2, p.111-118, 2007.

LANDELL, M.G.A.; CAMPANA, M.P.; FIGUEIREDO, P.; VASCONCELOS, A.C.M; XAVIER, M.A.; BIDOIA, M.A.P.; PRADO, H.; SILVA, M.A.; DINARDO-MIRANDA, 
L.L.; SANTOS, A.S.; PERECIN, D.; ROSSETTO, R.; SILVA, D.N.; MARTINS, A.L.M; GALlO, P.B.; KANTACK, R.A.D.; CAVICHIOLI, J.C.; VEIGA FILHO, A.A.; ANJOS, I.A; AZANIA, C.A.M.; PINTO, L.R.; SOUZA, S.A.C.D. Variedades de cana-de-açúcar para o Centro-Sul do Brasil. Campinas: Instituto Agronômico, 2005. 33p. (Boletim Técnico, 197) MACHADO, R.S.; RIBEIRO, R.V.; MARCHIORI, P.E.R.; MACHADO, D.F.S.P.; MACHADO, E.C.; LANDELL, M.G. de A. Respostas biométricas e fisiológicas ao déficit hídrico em cana-de-açúcar em diferentes fases fenológicas. Pesquisa Agropecuária Brasileira, v.44, p.1575-1582, 2009.

MUNNS, R; JAMES, R.A.; GILlIHAM, M.; FLOWERS, T. J.; COLMER, T. D. Tissue tolerance: an essential but elusive trait for salt-tolerant crops. Functional Plant Biology, Melbourne, v.43, n. 12, p. 1103-1113, 2016. Disponível em: < https://doi.org/10.1071/FP16187 >.

SILVA, M. de A.; JIFON, J.L.; SILVA, J.A.G. da; SANTOS, C.M. dos; SHARMA, V. Relationships between physiological traits and productivity of sugarcane in response to water deficit. Journal of Agricultural Science, Cambridge, First View, doi: 10.1017/S0021859612000834, 2013.

SIMÕES, W,L.; CALGARO, W.; COELHO, D.S.;SANTOS, D.B.; SOUZA,M.A. Growth of sugar cane varieties under salinity. Revista Ceres, Viçosa, v. 63, n.2, p. 265-271, mar/abr, 2016. Doi: 10.1590/0034-737X201663020019

TAIZ L \& ZEIGER E (2013) Fisiologia Vegetal. 5 ${ }^{\mathrm{a}}$ ed. Porto Alegre, ArtMed. 954p.

WILLADINO L, OLIVEIRA FILHO RA, SILVA EA, GOUVEIA NETO AS \& CAMARA TR (2011). Estresse salino em duas variedades de cana-de-açúcar: enzimas do sistema antioxidativo e fluorescência da clorofila. Revista Ciência Agronômica, 42:417-422. Doi:10.1590/S1806-66902011000200022. 